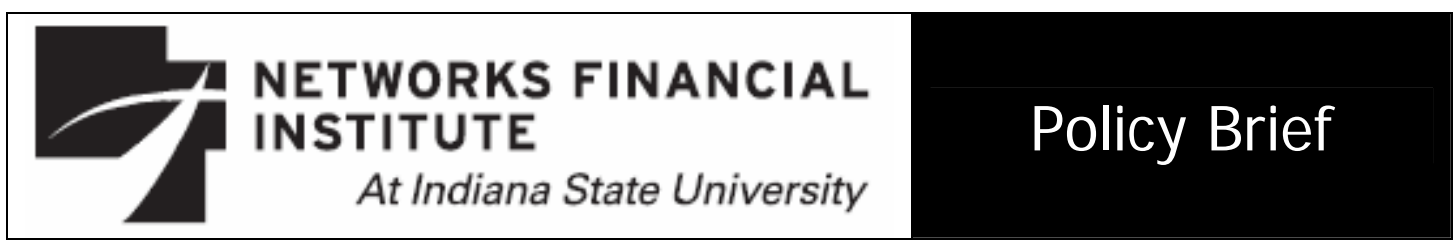

2006-PB-16

August 2006

\title{
Health Care Reform in the United States: Why, When and How?
}

\section{Douglas Holtz-Eakin}

Abstract: Why should the United States engage in broad reform of its health care? Because it must. When should health care reform begin? Yesterday would be best, but today for sure. And how should reform be done? It should focus on continuous incremental changes to the cultural, legal, and regulatory environment that improve the capacity of health care markets.

About the Author: Douglas J. Holtz-Eakin is Director of the Maurice R. Greenberg Center for Geoeconomic Studies, Council on Foreign Relations and holds its Paul A. Volker Chair in International Economics; he is Former Director of the Congressional Budget Office. As head of the CBO, Mr. Holtz-Eakin was the legislature's chief numbers cruncher, giving lawmakers objective and independent analysis of the fiscal effects of proposed laws. Dr. Holtz-Eakin served for 18 months as Chief Economist for the President's Council of Economic Advisors and for two years as Senior Staff Economist. Dr. Holtz-Eakin's research has focused primarily on two broad areas: economic policy and entrepreneurship and the economics of the estate and gift tax. He has an ongoing interest in tax policy, the economics of aging, and the political economy of growth.

Keywords: Health care reform, health care spending

The views expressed are those of the individual author and do not necessarily reflect official positions of Networks Financial Institute. Please address questions regarding content to Douglas Holtz-Eakin at dholtzeakin@cfr.org. Any errors or omissions are the responsibility of the author.

NFI working papers and other publications are available on NFI's website (www.networksfinancialinstitute.org). Click "Research" and then "Publications/Papers." 


\section{Health Care Reform in the United States: Why, When and How?}

\section{Douglas Holtz-Eakin}

Health care spending is the United States' leading economic and social policy challenge. In 1970 national health expenditures were \$1300 per person and consumed 7 cents out of every national dollar -7 percent of Gross Domestic Product (GDP). Over the past three decades, spending per capita grew on average 2.5 percent faster every year than did income per capita. The upshot of this phenomenon - which I will refer to as “excess cost growth" - is that in 2004 spending per capita rose to $\$ 6300$ and health spending constituted 16 percent of GDP.

What happened? While most of the recent attention has been paid to spending on drugs - which grew at an annual rate of 14 percent between 1997 and 2002 - this misses the bigger picture. Pharmaceuticals are still only 10 percent of the health care bill. Instead, the rising spending comes from several sources. The first is an aging population in which a larger fraction of the population is in high-spending parts of the life-cycle. Along with this has come rising incomes and increased health insurance coverage. The former increase the ability and the latter increases the incentives to purchase more health care. At the same time, the tort system has likely contributed to excessive testing and other forms of defensive medicine, although the exact scale is far from clear.

However, most analysts agree that a dominant characteristic of rising health spending has been the innovation, adoption, diffusion, and utilization of new technologies. While in some cases these new technologies held out the promise of comparable cost-savings elsewhere - think, for example, of cholesterol medications reducing the utilization of heart bypass or angioplasty - thus far such savings have not been realized. And in many cases, innovation simply permitted the treatment of previously-untreated chronic conditions ranging from pain to erectile dysfunction to heartburn. 
These trends cannot continue. To see this, focus for a second on the U.S. federal government budget. ${ }^{1}$ At present, the ratio of debt (in the hands of the public) to GDP is roughly 40 percent. This ratio has two desirable characteristics as an indicator the long-run sustainability of current policies. First, the numerator reflects any cumulative mismatch between the outlays of the government and it tax receipts which is the core concept of sustainability. Second, the denominator reflects the scale the national economy that could, in principle, be devoted to the imbalance. Moreover, to the extent that there are pro-growth policies that might worsen the numerator, but sufficiently augment economic growth then the indicator will decline. This is exactly the type of sustainability barometer that one should examine.

Using this, let us examine the political and policy mechanics of trying to sustain something close to current federal budget practice. At present, the federal government raises about 18 percent of GDP in receipts - essentially the postwar average. (Business as usual in the United States is that the federal government spends 20 cents out of every national dollar, raises 18 cents in revenue, and borrows the remainder. This is nearly identical to how the federal government will close the books for 2006.)

On the spending side, let us assume that Social Security reform remains unrealized and the benefits are paid a currently scheduled. That implies that outlays for Social Security will rise with the retirement of the baby-boom generation from about 4.5 percent of GDP now to 6.5 percent of GDP in 2030, and then continue to drift north to about 7 percent of GDP.

Of course, this will require a bit of belt-tightening, so let us adopt the Administration's strategy of holding non-defense discretionary spending flat in nominal terms. But instead of holding it for five years, assume that the political will

\footnotetext{
${ }^{1}$ This discussion is based on the Congressional Budget Office, The Long-Term Budget Outlook, December 2005.
} 
exists to hold it flat for five decades. At the same time, cut defense discretionary spending by about 25 percent and hold it flat for 50 years. This is a dramatic reversal of the cost of current policy in both the supplemental (Iraq, Afghanistan, etc.) and base defense budgets and will carry comparably dramatic political costs.

Is this fiscal policy sustainable? Not yet. Having succeeded in 50 years of annual political self-control, the only element missing to keep a stable debt-to-GDP ratio is....a miracle! Specifically, the rate of excess cost growth must fall to: zero. If excess cost growth continues at historic rates, Medicare and (the federal share of) Medicaid will raise from 4 percent of GDP to 22 percent of GDP in 2050, or larger than the entire federal budget. Conventional assumptions (such as those of the Medicare trustees) are that excess cost growth will moderate to 1 percent. With this assumption, Medicare and Medicaid will still triple in size to 12 percent of GDP and debt-to-GDP will still grow explosively.

Future health care costs are of such magnitude that even if the "good news" scenario of 1 percent excess cost growth prevails and taxes are also raised to 25 percent of GDP fiscal policy is likely unsustainable. Moreover, the detrimental economic growth consequences of that size increase in taxes would reduce GDP enough to make the problem even harder to solve. Put bluntly, we cannot tax our way out fiscal implications of growth in federal health programs. We cannot grow our way out - a sustained increase in productivity growth of a full percentage point is both unimaginable and in adequate.

But the future of the federal government budget is not the most important reason why things must change. A bigger issue is the macroeconomic consequences of these trends. If left unchecked, these programs' enormous appetite for spending will attack the three pillars of post-war economic success.

First, U.S. economic success is largely due to the strength of the private sector. The mirror image of reliance on private markets is commitment to a government sector 
that is relatively small (granted, "small” is in the eye of the beholder) and contained. Growth in spending of the magnitude promised by current laws guarantees a much larger government.

Second, the small U.S. government has been financed by taxes that are relatively low by international standards and interfere relatively little with economic performance (the same caveat applies to "low" and "little”). Spending increases of the type currently promised guarantees higher taxes and impaired economic growth.

Finally, a hallmark of the U.S. economy has been its ability to flexibly respond to new demands and disruptive shocks. In an environment where old-age programs consume nearly every budget dollar, to address other policy goals politicians may resort to mandates, regulations, and the type of economic handcuffs that guarantee lost flexibility. Why should the government book the costs of homeland security, or worker training, or new initiatives when it can demand that the private sector do it "free"?

In short, addressing health care spending and fiscal sustainability is essential to sustaining overall economic growth in the United States.

In doing so, it is important to recognize that the problem is not necessarily the structure of federal programs. While they are large-scale customers and have a significant influence, the focus should be on the rising spending on health care excess cost growth exists in federal programs, state programs, and the private sector. However, the biggest problem is not how to cut health spending. The biggest problem is that we have no idea what we're getting for our money.

Does higher spending reflect better quality? Does it reflect market power or even predatory prices? Is it driven by overuse of new technologies, or under-utilization of preventive care that would avoid the need for expensive therapies? Is it an artifact of paper filing systems? Until the causes of the relentless rise in spending are more 
completely diagnosed it will be difficult to undertake effective reforms. In the absence of solid understanding, sensible reforms are impossible. Given current trends, in the future the government will find a way to devote fewer resources to health programs, but without better knowledge it will be easy to fear that any increased spending is waste, and any cuts in outlays comes at the expense of needed care. In that political environment, real reform will be impossible.

The sooner the reform process begins, the more beneficial the likely outcome. Suppose that policies remain unchanged. How would current trends indicate the future will evolve? In the private sector, it is likely that there would be rising reliance on employees bearing co-payments and a greater share of health insurance premiums. As these fail to control costs, fewer employees will likely be offered employee-sponsored insurance and the already-anemic individual market will diminish further. The upshot will be pressure on firms' bottom lines and households' pocket books.

Meanwhile, the same pressure on costs in the public sector will likely force states to scale back Medicaid coverage to the poorest of the poor. At the federal level, the rising cost of Medicare will consume greater and greater amounts of general revenues as, by design, premiums cover only one-quarter of outpatient physician drug costs. Under provision in the recent prescription drug legislation, the Medicare Modernization Act (MMA), the President and Congress will be under sustained pressure to reign in costs. The upshot will be a political crisis at both the state and federal level.

If left to this path, the most likely responses will be the ones easiest to directly "solve" the problem. On the insurance front, there will be tremendous pressure to expand Medicare eligibility. (There are early indications of the shape of such a response in Congressman Dingell's Medicare for All Act (H.R. 4863) that would dramatically expand fee-for-service Medicare.) On the health care cost side of the 
ledger, there will be simultaneous pressures to control prices and raise taxes to cover costs.

Less dramatic actions will simply pale compared to the problem. For example, raising the part B premium from 25 percent to 50 percent of outpatient care costs would reduce Medicare by only 0.7 percent of GDP in 2050. In short, failing to change course soon raises the odds of a future of higher taxes, greater government insurance, and more government price controls in health care.

What's a better solution? I think the U.S. will need to rely on market forces more, not less. Markets forces sometimes are scary and raise the specter of people getting cut out of health care. But making health care more like a business will inevitably lead to better understanding of the costs of health care. It will lead to more reasonable adoption and use of new diagnostic tools and therapies. No industry should adopt every new-fangled production technique regardless of its cost. Providing better incentives might lead to slower cost growth; it will certainly lead to better use of the money.

The first step is to begin to separate the markets for health care and health insurance. Health care is about getting the highest quality, lowest-cost bang for the buck as patients and doctors choose therapies. Health insurance is about making sure that family finances survive the economic consequences of episodes of bad health. At present, insurance and care are too intermingled in the United States. Reforms should target the two separately.

To improve private health insurance markets it is important to recognize that catastrophic and chronic costs are not the same. Insurance markets easily spread the costs and make affordable the high cost of infrequent episodes of bad health. But the ongoing high cost of chronic bad health is not insurable. At present, it is too difficult to identify these costs; the result is that insurance companies fear selling to individuals out of fear that they may turn out to be a chronic drain on profits. To 
support broad, private markets tax policy should eliminate the preferred status of employer-provided insurance. And, to the extent necessary, government high-risk pools or reinsurance should help to separately pay for chronic care. These reforms coupled with sensible regulations and tort laws - promise to broaden insurance pools and support making affordable insurance for the currently uninsured.

However the heart of the reforms needed is to make health markets work more like other markets. To begin, the United States has to establish a locus of decisionmaking that is conscious of costs and capable of evaluating benefits. Who will that be? Operating by process of elimination, it will not be insurance companies. Insurance companies shouldn't be in the business of micromanaging ordinary care, and the widespread discontent with Health Maintenance Organizations (HMOs) in the 1990s suggests they won't be. Similarly, it does not seem likely that Americans will place doctors at the controls of both care choices and costs. Finally, I do not envisage the public accepting government as the decider of care decisions and a full payer of health costs.

That leaves the U.S. family as the locus of decision-making. In a better-function market for health care, families would decide benefits in recognition of their costs. The result would be health decision-making that endorsed spending that is "worth it" - it might involve spending more as incomes and ages rise, but it would be efficient in its use.

The problems in fulfilling this vision exist in the cultural, benefits, and costs dimensions. Culture might be the hardest. At present, families do not expect to be in charge of health decisions and changing the culture from one in which people "visit" the doctor to one in which they "buy doctor services" is an enormous undertaking.

Moreover, even if the culture shifted instantly, there is much to be done in other areas. At present, too little is known about the benefits of alternative therapies to support good decision-making. As with other complicated consumer activities - 
homes, colleges, computers and cars come to mind - greater production and dissemination of information, evaluation and rankings must become routine.

On the cost side, it is similarly unimaginable that families could immediately shoulder the full burden of non-catastrophic health costs. However, moving to greater cost-exposure over time will give providers incentives to operate more efficiently and identify costs with better pricing. The large results will likely derive from more sensible technology adoption. Faced with regular evaluation of benefits and a clear importance of costs, technology adoption will satisfy an economic test and not just a health care hurdle.

A large of array of supportive changes could help to ensure success - tort reform, better physician training and best practice protocols, cross-state insurance portability, etc. - but government programs should take a lead in supporting reform. Medicare and Medicaid are on track to swamp the federal budget, which is reason enough for changing these programs. But changes should support reforms of the broader health sector - programs should provide information about quality, harness market forces in care decisions, and separately address catastrophic and chronic care. States face budget pressures, but corresponding incentives to innovate in providing low-income insurance - experimentation of this sort are a good thing.

Health care reform is a volatile, two trillion dollar brew of equipment, technicians, providers, patients, and insurers. Because there is no single magic bullet, a long series of adjustments will ultimately be required to ensure that the United States does not overspend on health care. The odds of getting all those changes right in one fell swoop are essentially zero, so a better approach is to begin now and make sustained, incremental improvements in the functioning of key markets.

Why should the United States engage in broad reform of its health care? Because it must. When should health care reform begin? Yesterday would be best, but today for sure. And how should reform be done? It should focus on continuous 
incremental changes to the cultural, legal, and regulatory environment that improve the capacity of health care markets. 